\title{
Fabrication of aluminum matrix composites reinforced with Al2ZrO5 nano particulates synthesized by sol-gel auto-combustion method
}

\begin{abstract}
Nanocrystalline Al2ZrO5 with particle size of about $38 \mathrm{~nm}$ was directly synthesized by combination of sol-gel auto-combustion and ultrasonic irradiation techniques from metal nitrates and glycine as precursors. The overall process involves formation of homogeneous sol, formation of dried gel and combustion process of the dried gel. Aluminum alloy matrix composites reinforced with $0.75 \%, 1.5 \%$ and $2.5 \% \mathrm{~A} 2 \mathrm{ZrO} 5$ nanoparticles were fabricated via stir casting method and the fabrication was performed at various casting temperatures. The resulting composites were tested for their nanostructure and present phases by SEM and XRD analysis. Optimum amount of reinforcement and casting temperature were determined by evaluating the density, hardness and compression strength of the composites. Al matrix alloy reinforced by $\mathrm{Al} 2 \mathrm{ZrO} 5$ nanoparticles improves the hardness and compressive strength of the alloy to maximum values of BHN 61 and $900 \mathrm{MPa}$, respectively. The most improved mechanical properties are obtained with the specimen including $1.5 \% \mathrm{Al} 2 \mathrm{ZrO} 5$ produced at $850{ }^{\circ} \mathrm{C}$.
\end{abstract}

Keyword: MMCs; Al2ZrO5; Nanostructure; Auto-combustion; Ultrasonic; Stir casting; Mechanical. 